\title{
Vectors for the development of high-tech industrial aquaculture
}

\author{
E. M. Romanova ${ }^{1 *}, V . V$. Romanov $^{2}, V . N$. Lyubomirova $^{1}, L . A$. Shadieva $^{1}$, and T. M. Shlenkina ${ }^{1}$ \\ ${ }^{1}$ Department of Biology and Ecology, Ulyanovsk State Agrarian University named after P.A. Stolypin, 432017 Ulyanovsk, Russia \\ 2 Department of Informatics, Ulyanovsk State Agrarian University named after P.A. Stolypin, 432017 Ulyanovsk, Russia
}

\begin{abstract}
The article discusses the prospects of optimizing the technology of growing African catfish in high-tech industrial aquaculture. The goal was to determine the range of biologically active substances that can increase the productivity, organoleptic qualities of fish grown in recirculating aquaculture systems and optimize their living conditions. For this purpose, a complex of biologically active substances was tested, including probiotics, prebiotics, amino acids, and natural sorbents. It was introduced into feed and added to the water of fish tanks. Studies have shown that the developed complex of biologically active substances accelerates growth and development, guarantees the growth of fish biomass, reduces the level of bacterial pollution of the fish habitat, and normalizes hydrochemical parameters in the tanks. Improving the technology of fish farming in recirculating aquaculture systems (RAS) involves changing the ideology of feeding and keeping fish. The results of our studies show that, under conditions of artificial breeding in RAS, it is necessary to use cultures of living microorganisms - probiotics that improve intestinal microbiocenosis in fish feeding and introduce them into the fish habitat. Probiotics should be used with prebiotics containing vitamin-amino acid complexes that stimulate the development of symbiotic microbiota. The use of natural sorbents plays an important role. The proposed set of ingredients increases the organoleptic qualities of fish. The studies were supported by the Russian Foundation for Basic Research with grant 18-016-00127.
\end{abstract}

\section{Introduction}

One of the ways to solve the problems of saturation of the fish market, import substitution and ensuring food safety is the accelerated development of domestic aquaculture. In recent years, industrial aquaculture has played an important role in domestic aquaculture. In its development, it focuses on the latest achievements in industrial breeding systems - on the installation of recirculating aquaculture systems (RAS) [1].

The advantages of this type of aquaculture over the others are obvious, because they make it possible to get large volumes of products year-round, accelerate fish growth processes, adjust habitat parameters, optimize feeding parameters, monitor the sanitary regime, and prevent fish diseases [2].

Artificially bred fish can be delivered to the consumer year-round in a live and fresh form. In many respects, it is not inferior to fish from natural reservoirs, and in some cases it also surpasses it with respect to a set of parameters of nutritional value. Fish grown under human control can be programmed to have the desired content of vitamins, amino acids and other biologically active substances, making it a product of functional nutrition $[3,4]$.
All these are the advantages of industrial fish farming. However, the organoleptic characteristics are a significant drawback of fish grown in RAS. First of all, it is a characteristic unpleasant aftertaste of the compound feed on which it is grown. This is one of the main reasons for the negative consumer attitude towards domesticated fish. The consumer prefers wild fish that lives in natural aquatic ecosystems and has a traditional fish taste and smell [5-7].

With regard to livestock products, the situation throughout the world is different. The consumer prefers meat of domesticated farm animals to meat of wild species. Technologies in animal husbandry have gone beyond technology in fish farming. The taste of meat of farm animals grown in feeding complexes and farms does not cause consumer complaints.

It is necessary to find vectors for the development of high-tech industrial culture, which, just like in meat farming, would produce fish of high quality and impeccable taste, which for consumers would be preferable to wild fish.

To create an ecologically safe product with high taste characteristics in industrial aquaculture, it is necessary to search for new directions for its development that will make this product competitive in the fish market both in terms of consumer qualities and in terms of price. At the same time, the priority is precisely the taste qualities for which fish is traditionally valued [8-11].

\footnotetext{
* Corresponding author: vvr-emr@yandex.ru
} 
Fish around the world is considered a popular healthy and wholesome food. It is one of the staple foods and is perhaps the most valuable of them. Fish contains a large amount of easily digestible protein containing essential amino acids that the human body does not synthesize itself, such as lysine, methionine, tryptophan, they are called limiting ones [12].

Fish is a complete protein food product. Omega-3 fatty acids, which play an important role in the prevention of cardiovascular diseases, as well as essential fatty acids that are not synthesized by the human body, give fish special value as a healthy food [13].

Fish contains a large amount of minerals, primarily calcium, which, together with phosphorus plays an important role in the formation of bone tissue, phosphorus, in turn, is necessary for the immune system, for the regulation of carbohydrate metabolism and is involved in a number of other metabolic processes in the body. Fish is also rich in iodine, essential for the endocrine system, in selenium, zinc and a wide range of trace elements [14].

Why does the consumer, choosing a product, prefer wild fish, rather than domesticated one, grown in conditions of artificial breeding? In this choice, the widespread erroneous opinion that only marine fish can be a product of a healthy diet plays an important role. And also the fact that fish is valued for its taste first of all and only secondarily for the composition of its nutrients $[15,16]$.

Focusing on taste, it should be noted that this is the main disadvantage of domesticated fish. Heat treatment or salting fish does not save fish from this taste of compound feed.

Fish breeders are trying to get rid of the specific aftertaste of compound feed by conducting pre-sale preparation, stopping feeding 3-6 days before the sale. An unpleasant specific taste becomes less pronounced, but this procedure does not solve the problem in full. In terms of taste, even after pre-sale preparation, domesticated fish cannot be confused with wild fish [13].

It should be recognized that at the present stage of development of industrial aquaculture technologies, fish produced using industrial cultivation technology in terms of its taste cannot compete with wild fresh fish.

So far we have discussed only the effect of compound feeds on taste, however, there are other negative aspects of high-tech industrial aquaculture that affect the quality of fish. In particular, feed for fish, for preventive purposes, often contains antibiotics. When using such feeds, traces of antibiotics in fish meat are preserved for more than six months [16]. This makes the fish grown on mixed feeds potentially dangerous for the consumer. And this is unacceptable.

An equally important negative factor in industrial fish farming systems is the high level of bacterial contamination of the fish habitat and their organism. Fish in RAS releases a large amount of organics into the aquatic environment in the form of metabolic products. Microbiota is rapidly developing on it. An increased level of bacterial contamination is characteristic not only for the aquatic environment, but also for meat and internal organs of fish. This negatively affects the consumer qualities of the fish, its environmental cleanliness and, of course, taste.

Today, the food industry around the world is focused on the production of healthy foods [17]. Consumer health and product quality are top priorities for ISO (International Organization for Standardization) standards developers. In product quality standards, an important role is given to organoleptic evaluation.

In particular, such organoleptic indicators as taste and smell play one of the main roles in consumer choice of food products, determining their market value. It is according to organoleptic assessment that the consumer makes a choice - to make a purchase or not.

In the conditions of modern civilization, which places high demands on the safety and quality of food products, it is necessary to improve industrial aquaculture and look for new vectors for its development that could increase its productivity and quality indicators of farmed fish so that it can compete with wild fish.

The problem of improving the quality, environmental cleanliness, organoleptic characteristics of fish grown in industrial high-tech aquaculture is important, relevant and needs to be addressed, since it is directly related to the problem of public health.

The aim of our work was to search for new technological solutions to improve the quality characteristics of fish farmed in high-tech industrial aquaculture.

In our study, we tested new technological solutions based on the use of a complex of biological substances during the cultivation of fish in industrial aquaculture, including spore forms of probiotics, prebiotics, zeolites and an amino acid concentrate.

\section{Materials and methods}

The object of the study was an African catfish, at the age of 4 months, cultivated in RAS. For research, two groups - the experimental and control one were formed, with 25 specimen in each. The control group followed a traditional feeding technology program. And the experimental group feeds received an elaborate complex consisting of probiotics, prebiotics, amino acids, zeolite (diatomite) as a part of feeds. The composition of this complex is shown in table 1.

Table 1. The composition of the ingredients of biologically active substances introduced into the feeds

\begin{tabular}{|l|c|}
\hline \multicolumn{1}{|c|}{ Ingredients } & $\begin{array}{l}\text { Quantity per } \\
1 \mathrm{~kg}\end{array}$ \\
\hline Probiotic Sporothermin, $\mathrm{g}$ & 4.0 \\
\hline Zeolite, g & 10.0 \\
\hline $\begin{array}{l}\text { AMINOBIOL amino acid } \\
\text { concentrate, ml }\end{array}$ & 0.3 \\
\hline Prebiotic CHIKTONIC, ml & 1 \\
\hline
\end{tabular}

The probiotic sporothermin is a powdery preparation that consists of the spore-forming bacteria Bacillus subtilis and Bacillus licheniformis. Sporothermin is a 
pathogen antagonist and an alternative to antibiotics. The drug was developed by the production association VetSelkhoz (Russia). Its purpose is normalization of intestinal microbiocenosis of fish, increase in natural resistance, reduction of stress level, prevention and treatment of infectious diseases.

Prebiotik Chiktonik is a liquid vitamin and amino acid preparation of the Spanish manufacturer Invesa.

Zeolites are $\mathrm{Ca}$ and $\mathrm{Na}$ aluminosilicates containing water, much less often other chemical elements are present in their composition. They have adsorption, ion exchange, catalytic properties. Dehydrated zeolites acquire the ability to absorb organics and are highly effective natural sorbents. It is these properties that have oriented us to the use of zeolites in fish farming as a part of fish feed. In our studies, we used natural zeolites of the Ulyanovsk deposit - diatomites, the main component of which is silicon, the content of which can reach 80$90 \%$.

All components of the feed additive were diluted in $250 \mathrm{ml}$ of water and $1 \mathrm{~kg}$ of feed was soaked in with this mixture. The composition of the used food "SomRost" of AQUAREX company are shown in table 2.

Table 2. The composition of the feed for fish of the control group.

\begin{tabular}{|l|c|}
\hline SomRost feed & $39 / 11$ \\
\hline Digestible energy, MJ/kg & 17.1 \\
\hline Crude protein, \% & 39 \\
\hline Crude fat, \% & 11 \\
\hline Fiber, no more than, \% & 2.5 \\
\hline Ash, no more than, \% & 10 \\
\hline Lysine, \% & 1.8 \\
\hline Mass fraction of phosphorus, \% & 1.2 \\
\hline $\begin{array}{l}\text { Mass fraction of methionine and } \\
\text { cystine, \%, }\end{array}$ & 0.9 \\
\hline
\end{tabular}

Feeding was carried out twice a day; in the morning and evening. Feed consumption was $2-3 \%$ of the weight of fish in the experimental and control groups.

For microbiological studies, water samples were taken in compliance with sterility conditions. The determination of the number and isolation of pathogenic and opportunistic bacteria was carried out immediately after sampling. To study the morphological, cultural and biochemical properties of bacteria, they were sown on solid nutrient media of general purpose - meat-peptone agar in triplicate. Selective selection of fungi was carried out on Saburo medium. Endo selective medium was used to isolate enterobacteria.

Ploskirev's medium was used to identify pathogenic microbiota. Microorganisms were identified by Bergey's manual. Bacterioscopy was performed to assess the total microflora in $1 \mathrm{ml}$. water. The growth rate of microorganisms was ranked: confluent growth -108 cells, massive growth -107 cells, moderate growth 105 cells, meager growth -104 cells in $1 \mathrm{ml}$ of water $[1,14]$.
When studying the effect of probiotic, prebiotic and zeolite on the hydrochemical composition of water in addition to feed, in the experimental group the ingredients were introduced directly into the water (table 3).

The probiotic sporothermin was added to the aqueous medium in an amount of $4 \mathrm{~g}$ per 1001 of water, the prebiotic chiktonik - in an amount of $1 \mathrm{ml}$ per 1001 of water, zeolite at the rate of $10 \mathrm{~g}$ per $100 \mathrm{l}$ of $\mathrm{H} 2 \mathrm{O}$. The probiotic, prebiotic and zeolite were not introduced into the tank which contained the control group.

Table 3. Composition of a mixture of biologically active substances introduced into the tank water

\begin{tabular}{|l|c|}
\hline \multicolumn{1}{|c|}{ Ingredients } & $\begin{array}{c}\text { Amount per } \\
100 \mathrm{~L} \mathrm{H}_{2} \mathrm{O}\end{array}$ \\
\hline Probiotic Sporothermin, g & 4.0 \\
\hline Zeolite, g & 10.0 \\
\hline $\begin{array}{l}\text { AMINOBIOL amino acid } \\
\text { concentrate, ml }\end{array}$ & 1.0 \\
\hline Prebiotic CHIKTONIC, ml & 1.0 \\
\hline
\end{tabular}

Measurements of hydrochemical parameters of water were carried out every hour after feeding for 7 hours. The oxygen content and water temperature were determined using an Oximeter AZ8401 instrument. The $\mathrm{pH}$ values and other hydrochemical indices were determined using Tetra company chemicals.

Processing of research results was carried out using traditional biometric indicators.

The determination of the arithmetic mean was carried

where: $M$ - arithmetic mean; ${ }^{x_{i}}$ - values of variants; $n$ - number of observations.

The standard deviation $\delta$ was calculated by the formula:

$$
\delta=\sqrt{\frac{\left(M-x_{i}\right)^{2}}{n-1}} .
$$

The arithmetic mean error $m$ was calculated by the formula:

$$
m=\frac{\delta}{n-1}
$$

To determine the statistical significance of differences in the average values of the two samples, Student criterion $t_{s t}$ was used. To calculate the criterion, the expression was used:

$$
t_{p}=\frac{\left(M_{1}-M_{2}\right)}{\sqrt{\left(m_{1}^{2}+m_{2}^{2}\right)}} \text {. }
$$

The calculated value of $t_{p}$ was compared with the tabular value of the criterion $t_{\mathrm{st}}$ at the selected level of confidence probability $\mathrm{p} \leq 0.05$ and the number of degrees of freedom $i$. If the calculated value of the criterion $t_{p}$ $<\mathrm{t}_{\mathrm{st}}$, then the differences were evaluated as statistically unreliable. 


\section{Results}

The future of industrial aquaculture is associated with the development of new, more advanced ecologically safe technologies for fish farming, which will improve the consumer qualities of artificially bred fish, improve its organoleptic characteristics, ensure its environmental cleanliness and make it competitive in the fish market.

At the first stage of the research, we evaluated the effect of the elaborate complex of biologically active substances that we formed, the ingredients of which were added to the food and water of fish tanks.

For a month, we grew fish by introducing the probiotic sporothermin, the prebiotic chiktonik, zeolite, and the amino acid concentrate aminobiol into the feed for the experimental group. After a month, we evaluated the growth rate of fish cultivated on traditional and modified feeds. The research results are presented in Fig. 1.

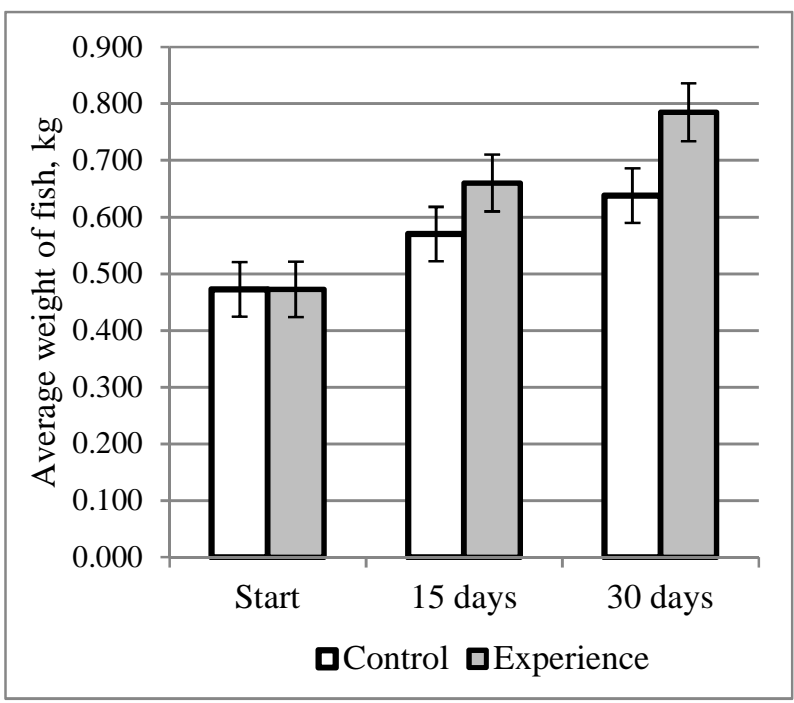

Fig. 1. The average weight of the fish in the experimental and control groups during the monthly experiment

Our results indicate that after a month an increase in fish biomass was detected in both the experimental and control groups. Over the month, the increase in the average weight of fish in the control group was $35.07 \%$, and in the experimental group, the increase was higher and amounted to $66.2 \%$.

At the beginning of the experiment, the average weight of fish at the age of 4 months was $0.472+0.049$ $\mathrm{kg}$. After two weeks, the average weight of fish in the control group was $0.570+0.048$, in the experimental group $0.660+0.050$. At the end of the experiment, i.e. a month later, the average weight of fish in the control group reached $0.638+0.051 \mathrm{~kg}$, in the experimental group $-0.785+0.510 \mathrm{~kg}$.

Research results indicate that weight gain was uniform in both the experimental and control groups. This means that the fish quickly adapted to the feed supplement we developed, which did not cause any stress for it, and against its background, on the 30th day of the experiment, it gained 23\% more weight gain than in the control group.

Next, we calculated the dynamics of the growth of fish biomass in the control and experimental groups during the monthly experiment. The results of the analysis of this process are shown in Fig. 2. The presented chart clearly demonstrates the difference in the growth of this indicator in the control and experimental groups.

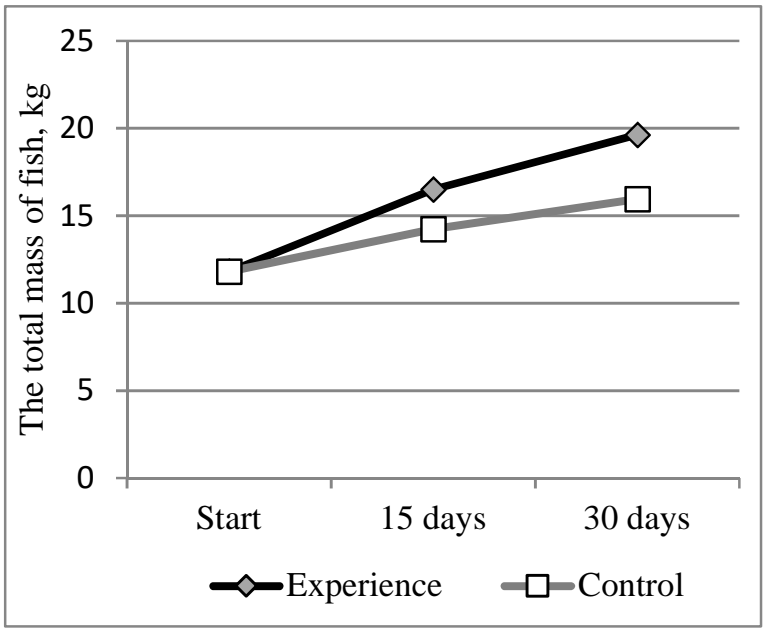

Fig. 2. The dynamics of the accumulation of fish biomass in the experimental and control groups during the experiment

At the second stage of the study, studies were conducted on the effect of biologically active substances - probiotics, prebiotics, zeolites - that we use in feeding on the formation of microbiocenosis of the fish habitat.

It is known that in industrial aquaculture, fish is the main factor in the organic pollution of the environment by its own metabolites entering directly into the water. A high level of organic pollution creates ideal conditions for the development of pathogenic and conditionalpathogenic microbiota.

The results of bacteriological studies at the start of the experiment showed the presence of the same microbiota in the water tanks with fish of the control and experimental groups. In particular, opportunistic bacteria Citrobacter freundii (Enterobacteriaceae family) and Enterococcus faecalis (Enterococcaceae family) were found. On nutrient media, their continuous growth was revealed, reaching $10^{8}$ cells.

Pathogenic forms of bacteria of the genus Citrobacter can cause gastroenteritis and foodborne toxicoinfections in fish. Identified bacteria $C$. freundii are gram-negative facultative anaerobes present in fish feces; Having multiplied in the intestine, they cause severe inflammatory processes of the intestinal tract. Enterococci E. faecalis found in the water of the tanks are indicative of fresh "fecal contamination." On nutrient media, their confluent growth was revealed $-10^{8}$ cells.

After the initial bacteriological examination, a complex of biologically active substances was introduced into the pool with fish of the experimental group: probiotic sporothermin prebiotic chiktonik, zeolite, amino acid complex, in the proportions set forth in table 3. 
Microbiological studies of water carried out a month later showed that in the tank with the experimental group of fish, against the background of the complex of biologically active substances that we developed, the presence of pathogenic and conditional-pathogenic microbiota sharply decreased by four orders of magnitude and amounted to $10^{4}$. The qualitative composition of the microbiota did not differ from that in the control tank.

Our results showed that the use of the probiotic sporothermin, the prebiotic chiktonik, zeolites, the amino acid concentrate aminobiol shifted the equilibrium in the aquatic microbiocenosis, sharply reducing the proportion of conditional-pathogenic microbiota in the fish habitat.

At the next stage of the work, we investigated how the complex of biologically active substances that we developed, supplied with feed and added directly to water affects the hydrochemical parameters of the water in the tank.

First of all, comparative studies were conducted to assess the level and rate of water pollution with nitrites and nitrates. The results are presented in table 4 . The results presented in the table demonstrate how the hydrochemical parameters of water in the experimental group change with the use of probiotics, zeolites, vitamins and amino acids. Observations of the hydrochemical regime in the tanks showed that throughout the experiment, the water quality corresponded to technological standards. After feeding, the dynamics of a number of indicators of water quality was observed.

Studies of the $\mathrm{pH}$ level showed that after feeding, the medium alkalized and the concentration of hydrogen ions increased to 8 units, sometimes exceeding this parameter. In the experimental tank with fish, alkalization was less pronounced and the concentration of hydrogen ions increased to a lesser extent, not exceeding 7.5 units.

The study of ammonia and ammonium 6 hours after feeding in the experimental pool was $2 \mathrm{mg} / \mathrm{l}$, while in the control tank the level of these toxicants in water reached $3.8 \mathrm{mg} / \mathrm{l}$.

As for the nitrite content, the following was established: in the control tank 5 hours after feeding, their content approached the upper limit of the norm and reached $0.25 \mathrm{mg} / \mathrm{l}$. In the tank with the experimental group, the nitrite level was two and a half times lower and amounted to $0.1 \mathrm{mg} / \mathrm{l}$.

Table 4. Characterization of the hydrochemical composition of water in the experimental and control tanks

\begin{tabular}{|c|c|c|c|c|c|c|}
\hline  & 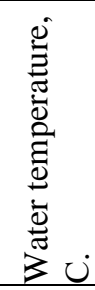 & $\begin{array}{l}\vec{\Xi} \\
\Xi \\
\bar{\Phi}\end{array}$ & 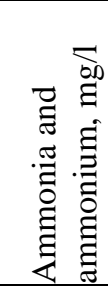 & 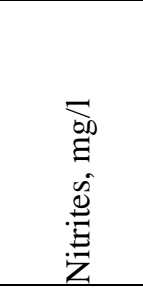 &  & 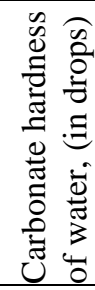 \\
\hline Hour & \multicolumn{6}{|c|}{ Experiment/Control } \\
\hline 1 & $26 / 26$ & $7 / 7$ & $0 / 0$ & $0 / 0$ & $0 / 0$ & $10 / 11$ \\
\hline 2 & $26 / 26$ & $7 / 7.5$ & $0 / 0.5$ & $0.05 / 0.05$ & $0 / 3$ & $9 / 9$ \\
\hline 3 & $26 / 26$ & $7 / 7.5$ & $0 / 1$ & $0.05 / 0.1$ & $2 / 5$ & $8 / 11$ \\
\hline 4 & $26 / 26$ & $7.5 / 8$ & $0.5 / 1$ & $0.05 / 0.2$ & $2 / 5$ & $9 / 10$ \\
\hline 5 & $26 / 26$ & $7.5 / 8$ & $0.5 / 1.5$ & $0.1 / 0.25$ & $4 / 8$ & $10 / 10$ \\
\hline 6 & $26 / 26$ & $7.5 / 8.3$ & $1 / 2$ & $0.15 / 0.25$ & $4 / 10$ & $10 / 9$ \\
\hline 7 & $26 / 26$ & $7.5 / 8.5$ & $2 / 3.8$ & $0.2 / 0.25$ & $5 / 15$ & $10 / 10$ \\
\hline
\end{tabular}

The nitrate content in 6 hours after feeding the fish of the control group grew and reached a level of $10-15 \mathrm{mg} /$ 1. In the experimental tank, this parameter also increased, but was more than 2.5 times lower and amounted to 4-5 $\mathrm{mg} / \mathrm{l}$. The carbonate hardness of water did not change during the experiment.

\section{Discussion}

The results of our studies have shown that the use of a complex of biologically active substances under conditions of artificial fish breeding can significantly stimulate this process for the better.

The results of the study of the growth rate, the total biomass increase in the experimental group significantly exceeded the results achieved in the control group. In the works published by us earlier, the positive effect of the probiotic sporothermin in the process of growing African catfish was already noted [18].
A high level of bacterial contamination in the fish habitat and in their bodies carries hidden dangers, starting from the earliest stages of ontogenesis. Pathogenic bacteria, colonizing the shell of the eggs, and then the embryo, subsequently colonize the intestines of the larvae. Against this background, fish larvae, starting from the early stages of ontogenesis, develop diseases that weaken the body, slow down the development and productivity of fish.

Testing the probiotic sporotermin to reduce bacterial seeding and normalize the microbiocenosis of African catfish eggs, we were convinced of its effectiveness [18]. Sporotermin is a preparation containing the sporeforming bacteria Bacillus subtilis and Bacillus licheniformis, designed to increase natural resistance, reduce the negative effects of stress, to prevent and treat infectious diseases, and normalize the microbial balance in the digestive tract of fish. Sporotermin is considered an antagonist of pathogens and is an alternative to 
antibiotics. The preparation does not adversely affect the fish organism at all stages of their ontogenesis.

When fish are grown under artificial conditions, natural processes of accumulation of metabolites in water occur, which, to a certain extent, do not adversely affect its growth and development. These limits determine the technological norm of water quality.

In the conditions of tank breeding, constant monitoring of such parameters as oxygen concentration, $\mathrm{pH}$, the content of ammonia, nitrates and nitrites in water is necessary. As a rule, an increase in the content of pollutants is observed after 4-6 hours after feeding.

Nitrites are an intermediate product of the incomplete oxidation of ammonia during the metabolism. Their content increases with a deficiency of microorganisms nitrifying agents. Nitrite is toxic to fish, already in a concentration in water up to $1-2 \mathrm{mg} / \mathrm{l}$. Fish can tolerate such concentrations for a short time, responding to them with a sharp decrease in growth rates.

At low pH values, the effect of nitrites is enhanced. Nitrates - the final product of biological purification, can accumulate in water in the absence of denitrification. Also, at high concentrations (more than $170 \mathrm{mg} / \mathrm{l}$ ), they have a negative effect on the metabolism and growth processes of fish; can cause a decrease in $\mathrm{pH}$, inhibiting nitrification processes.

The total content of ammonia and ammonium ion in water is the most important fish breeding indicator. Ammonia (NH3) has acute toxicity to fish. The ionized form of ammonia - ammonium ion (NH4+) - is harmful in chronic exposure. Its toxicity is especially pronounced at low values of water hardness. The total indicator (NH3 and NH4+) for the artificial keeping of fish is the most important factor limiting fish-holding density. Changes in the hydrochemical parameters of water in the pool serve as an indicator of the state of fish, especially in a stressful situation.

Summarizing the results of a study of the hydrochemical composition of water, it should be noted that the feeding process affects the qualitative characteristics of the water in the tank. The level of toxicants in the water of fish tanks after feeding was progressively increasing for 5-6 hours. This is expressed in a change in the main indicators of water quality $\mathrm{NH} 3$ /NH4+, nitrates and nitrites in the control tank. In the experimental tank, the growth of the main indicators and toxicants was two times lower.

\section{Conclusion}

The complex of biologically active additives developed by us increases the growth and development rates of fish, and allows maintaining the most important hydrochemical parameters in the tanks, such as $\mathrm{pH}$, ammonia/ammonium, nitrite, and nitrate contents within the normal range. This provides fish with comfortable living conditions and increases production rates.

The use of the probiotic sporothermin, the prebiotic chiktonik zeolite (diatomite), and the amino acid concentrate has a positive effect on the hydrochemical composition of water, due to the bacteria Bacillus subtilis and Bacillus licheniformis, the ion-exchange properties of zeolite and the biochemical properties of the remaining ingredients that are a part of the biologically active complex of substances we developed, that we added to feed and tank water.

The accelerated development of industrial aquaculture and its qualitative parameters is necessary for objective reasons due to a sharp deterioration in the ecological state of aquatic ecosystems under the influence of anthropopression and technogenic pollution, which will only increase in the future. Fish from such water basins is a danger to the consumer. Therefore, the future of world fish farming is with high-tech industrial fish farming systems and large fish farming complexes, the technological process of fish growing in which needs to be further improved.

\section{References}

1. P.E. Garlov, N.B. Rybalova, E.D. Shinkarevich, T.A. Nechayeva, S.U. Temirova, B.S. Bugrimov, IOP Conference Series: Earth and Environmental Science, 403, 012038 (2019)

2. E. Romanova, M. Mukhitova, V. Romanov, V. Lyubomirova, L. Shadieva, T. Shlenkina, IOP Conference Series: Earth and Environmental Science, 403, 012121 (2019)

3. D. Pacetti, M. Mozzon, N.G. Frega, P. Lucci, Current nutrition and food science, 9(4), 283-297 (2013)

4. L.A.J. Nagelkerke, E. Van Onselen, N. Van Kessel, R.S.E.W Leuven, Plos One, 13(6), E0197636 (2018)

5. K. Grigorakis, Critical reviews in food science and nutrition, 57(14), 2956-2969 (2017)

6. T.N. Suhareva, I.V. Sergienko, IOP Conference Series: Earth and Environmental Science, 422, 012055 (2020)

7. S. Muizniece-Brasava, O. Dmitrijeva, I. Pilvere, M. Silovs, A. Nipers, 18th International Multidisciplinary Scientific Geoconference SGEM 2018 Conference Proceedings, 113-118 (2018)

8. L. Cooke, Agricultural research, 42(5), 22 (1994)

9. T. Marui, S. Kiyohara, Chemical senses, 12(2), 265 (1987)

10. H. Oike, T. Nagai, S. Okada, Y. Aihara, Y. Ishimaru, I. Matsumoto, T. Misaka, K. Abe, A. Furuyama, T. Marui, Journal of neuroscience, 27(21), 5584-5592 (2007)

11. S. Morais, Reviews in fisheries science and aquaculture, 25(2), 133-149 (2007)

12. Z. Usydus, J. Szlinder-Richert, M. Adamczyk, U. Szatkowska, Food chemistry, 126(1), 78-84 (2011)

13. S. Khalili Tilami, S. Sampels, T. Zajíc, J. Krejsa, J. Másílko, J. Mráz, Peer J., 6, E5729 (2018)

14. A. Paritova, N. Biltebayevna, G. Kuzembekova, Z. Valieva, D. Sarybaeva, Research for rural development 2011 - Annual 17th international scientific conference proceedings, 163-167 (2011) 
15. M. Mardani, M. Asadi-Samani, S. Rezapour, P. Rezapour, Evaluation of bred fish and seawater fish in terms of nutritional value, and heavy metals, Journal of chemical and pharmaceutical sciences, 9(3), 1277-1283 (2016)

16. L. Shadyeva, E. Romanova, V. Romanov, E. Spirina, V. Lyubomirova, T. Shlenkina, Y.
Fatkudinova, IOP Conference Series: Earth and Environmental Science, 403, 012218 (2019)

17. J. Swartzberg, Sh. Margen, American journal of epidemiology, 154(12), 1160-a (2001)

18. E.M. Romanova, V.V. Romanov, V.N. Lyubomirova, L.A. Shadyeva, T.M. Shlenkina, BIO Web of Conferences, 17, 00122 (2020) 